ISSN 1518-3483

Licenciado sob uma Licença Creative Commons

(c) (1)

\title{
Os desafios do conceito de experiência para pensar a profissionalização docente
}

\section{The challenges of the concept of experience to think about teacher professionalization}

\section{Los desafíos del concepto de experiencia para pensar la profesionalización docente}

\section{Lúcia Villas Bôas*}

Fundação Carlos Chagas (FCC), São Paulo, SP, Brasil,

Universidade Cidade de São Paulo (UNICID), São Paulo, SP, Brasil

\section{Resumo}

Presente há muito no campo conceitual educacional, as atuais discussões sobre os processos de formação e de profissionalização docentes têm, cada vez mais, colocado em evidência o conceito de experiência. Em que pese novas combinações de seu uso, tais como "saberes experienciais", "saberes da experiência", "formação experiencial", "experiência formadora", "experiência de vida" etc., as vias de construção da experiência, bem como a explicitação de seus significados, são ainda pouco analisadas. 0 objetivo desse texto é de

LVB: Doutorado em Educação: Psicologia da Educação e Engenharia dos materiais, e-mail: lboas@fcc.org.br 
explicitar as dificuldades em se trabalhar com esse conceito, haja vista sua polissemia e diversidade de entendimento. Para isso, ele está estruturado em duas partes. A primeira, apresenta a associação entre experiência e formação de adultos como fundamentada, em larga medida, em modelos teóricos em que esse conceito teve um papel preponderante (sobretudo J. Dewey, D. Kolb e M. Knowles). A segunda traz o recorte de uma pesquisa que, ao exemplificar a diversidade de entendimento da noção de experiência do ponto de vista dos professores, aponta para a necessidade de sua desnaturalização, de modo a discutir a diversidade de seus usos sobretudo no campo da formação e da profissionalização docentes.

Palavras-chave: Experiência. Formação de adultos. Profissionalização docente.

\begin{abstract}
Present a long time in the educational conceptual field, the current discussions about the teacher professionalization has, increasingly, discussed the concept of experience. Considering new combinations, such as "experiential learning", "knowledge of experience", "experiential training", "forming expereince", "life experience" etc., the forms of construction of experience and the explicitation about their meanings are few analyzed. The purpose of this article is to explicit the difficulties in working with this concept considering the big polysemy of meanings and diversity of understanding. For this, it is structured in two parts. The first one, has intend to present the association between experience and adult education, normally grounded in theoretical models in which this concept had a preponderant function (mainly by J. Dewey, D. Kolb e M. Knowles). The second part, will present a research excerpt that, shows the necessity of the denaturalization of "experience" for discuss the diversity of its applications, especially in the teachers formation and professionalization.
\end{abstract}

Keywords: Experience. Adult training. Teacher professionalization. 


\section{Resumen}

Con una prolongada presencia en el plano conceptual educativo, las discusiones actuales sobre la formación y profesionalización docentes se ha puesto cada vez más en evidencia el concepto de experiencia. A pesar de nuevas combinaciones de su uso, tales como "conocimiento experimental», "conocimiento de la experiencia», "formación experiencial», "experiencia formadora", "experiencia de la vida" etc., las vías de construcción de la experiencia y explicación de sus significados son aún poco analizadas. El objetivo de este artículo es explicar las dificultades de trabajar con este concepto teniendo en cuenta su diversidad de significados y comprensión. Para esto, se estructura en dos partes. La primera presenta la asociación entre la experiencia y la educación de adultos como fundamento, en gran medida, en los modelos teóricos en los que este concepto ha tenido un papel preponderante (especialmente J. Dewey, D. Kolb y M. Knowles). La segunda presenta parte de una investigación que indica la necesidad de desnaturalización del término "experiencia» con el fin de discutir la diversidad de sus usos, especialmente en el campo de la formación y de la profesionalización docente.

Palabras clave: Experiencia. Educación de adultos. Profesionalización docente.

\section{Introdução ${ }^{1}$}

Experiência não é o que acontece com você, mas o que você fez com o que lhe aconteceu.

Configurando-se como um vasto campo de pesquisa, a problemática da experiência está presente em diversas áreas do saber, tais como a filosofia, a psicologia, a etnologia, a antropologia, a sociologia, em distintos contextos e épocas. No âmbito educacional, isto também não é diferente. As atuais discussões sobre os processos de formação e de

1 A discussão aqui apresentada é parte da pesquisa "Experiência, historicidade e representações sociais: contribuição aos estudos educacionais", financiada pelo CNPq (Processo n. 471002/2013-5). 
profissionalização docentes têm, cada vez mais, colocado em evidência o conceito de experiência que, diferentemente de conceitos como "saberes docentes" e mesmo "profissionalização", cujos usos são mais recentes, faz parte, há muito tempo, do campo conceitual da educação, integrando o vocabulário daqueles que se interessam pelas atividades de intervenção sobre o outro.

É assim que, para se explicar como o adulto aprende, seja nas situações informais ou de formação formal, na vida cotidiana ou no ambiente de trabalho, são usados termos como "aprendizagem experiencial" (KOLB, 1984), "saberes experienciais" ou "saberes da experiência" (TARDIF, 1993), “formação experiencial” (LANDRY, 1989; DOMINICÉ, 1991), "experiência profissional” (THERRIEN, 1998), "experiências formadoras" e "experiências de vida" (JOSSO, 1991), noções também recorrentes nas discussões específicas sobre os processos de formação e de profissionalização docentes.

O uso do termo experiência tem se apresentado particularmente expressivo no âmbito da formação de adultos, sobretudo quando se trata de caracterizar e de analisar seus processos próprios de aprendizagens - por oposição à aprendizagem da criança ou do adolescente, consideradas como diferentes (MAYEN, 2009). Isso porque, aos adultos, se reconhece uma experiência sobre a qual se faz necessário considerar para o desenvolvimento de novas aprendizagens (ZEITLER; BARBIER, 2012), o que faz com que ela seja não apenas cada vez mais valorizada, no âmbito dessa formação, mas também cada vez mais reconhecida. Ainda assim, a consideração da experiência para obtenção de um diploma, título ou certificação profissional não é ponto pacífico, uma vez que, apenas recentemente, os dispositivos de educação e de formação têm integrado a experiência de jovens e adultos. Como afirma Robin (2009): "Apesar de seu alto valor de uso, a experiência ainda apresenta um baixo valor de troca" (p. 191, tradução nossa) na medida em que a norma social do diploma ainda se mantém válida² .

2 Pensa-se aqui, sobretudo, na proposta do Sistema Nacional de Certificação Profissional que trata do reconhecimento da experiência e de sua validação (BRASIL, 2005/2016). 
Mas do que se fala, quando o termo experiência é acionado? ${ }^{3}$ Uma rápida passagem pelo dicionário mostra as dificuldades em se trabalhar com esse conceito, haja vista sua grande polissemia e diversidade de entendimento, como se pode observar na figura 1 , que apresenta a nuvem lexicográfica formada a partir da consulta aos dicionários de uso corrente e à remissiva dos termos relacionados à experiência:

Figura 1 - Nuvem lexicográfica do termo indutor experiência

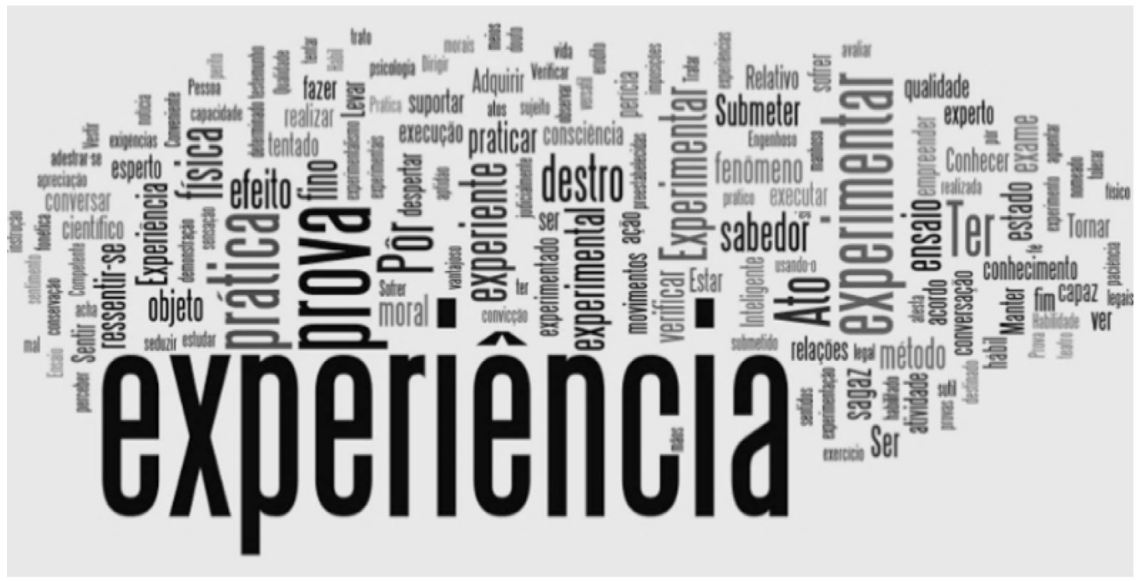

Fonte: Elaborado pela autora, 2016.

De modo geral, em uma acepção do senso comum, a experiência pode ser compreendida como o conhecimento adquirido pela prática. Essa simples definição esconde uma série de relações problemáticas das quais apenas duas são citadas, ainda que rapidamente. A primeira delas refere-se à relação entre teoria e prática.

3 Para uma discussão acerca dos usos do termo experiência em diferentes línguas, inclusive sua diferenciação em relação à vivência e à aprendizagem, ver Amatuzzi (2007) e Larrosa (2002). Para uma discussão crítica desses diversos usos, ver Zeitler e Barbier (2012). 
Essa definição de experiência contribui para a já tradicional separação entre esses dois elementos: ter experiência significa que esta foi adquirida pela e na atividade por oposição, justamente, a uma aplicação de saberes. No limite, tal definição do senso comum seria quase que uma desqualificação da teoria como estranha, ou mesmo um óbice, à própria ideia de experiência, como revela a frase tantas vezes dita: "Na prática, a teoria é outra".

Esse sentido corrente da experiência, paradoxalmente, daria, à prática, os atributos sociais da teoria: (caráter comprovado do saber e referência a uma autoridade), invertendo-os: "é porque a experiência foi vivida que ela apresenta um valor apoiado em uma eficiência pragmática, ou seja, a autoridade da experiência é dada justamente pela prática contra a teoria" (ZEITLER; BARBIER, 2012, s/p).

A segunda problemática, presente nessa acepção de senso comum, refere-se à relação entre experiência e prática: ainda que baseada em uma prática, a experiência não se confunde com ela e, nesse sentido, supõe processos específicos de construção (ZEITLER; BARBIER, 2012) que não caberia explicitar aqui.

No âmbito acadêmico, uma simples olhada para os trabalhos produzidos em diferentes campos do saber revela uma miríade de definições e uma diversidade de enfoques acerca dos usos da experiência. Com o intuito, então, de explicitar as dificuldades em se trabalhar com esse conceito, haja vista sua polissemia, este texto está estruturado em duas partes. A primeira apresenta a associação entre experiência e formação de adultos como fundamentada, em larga medida, implícita ou explicitamente, em modelos teóricos em que esse conceito teve um papel preponderante. Feitas essas considerações e para fornecer subsídios empíricos para a discussão que vem sendo realizada, a segunda parte trará alguns dados de uma pesquisa desenvolvida no âmbito da Cátedra UNESCO sobre Profissionalização Docente sediada no Centro Internacional de Estudos em Representações Sociais e Subjetividade - Educação da Fundação Carlos Chagas (São Paulo) que exemplifica as dificuldades de se trabalhar com o termo "experiência". 


\section{A noção de experiência em diferentes abordagens no âmbito da formação de adultos}

Sem ter a intenção de discutir essa questão desde uma perspectiva ontológica e sem desconsiderar os diferentes estudos existentes acerca dessa problemática, podem ser citados, particularmente, três autores que contribuíram para a presença e valorização da experiência nos processos de formação profissional, quais sejam: John Dewey, David Kolb e Malcolm Knowles, estes dois últimos também pioneiros da pesquisa sobre formação de adultos.

Embora Dewey não tenha se preocupado com a formação do adulto especificamente, seus estudos sobre educação e experiência ainda fundamentam um grande número de pesquisas sobre essa temática graças, sobretudo, à centralidade que a experiência ocupa em sua obra.

De acordo com Cometti (2012), a ambiguidade do termo experiência é uma fonte de dificuldade para Dewey. Ao afirmar a necessidade de esclarecê-lo, em Experiência e Educação (1938/2011), Dewey faz uma análise da experiência articulando-a ao movimento de reforma da educação progressista nos Estados Unidos, propondo alguns princípios que não caberia, nesse espaço, discuti-los.

Grosso modo, o que se gostaria de destacar é que, para Dewey (1938/2011; 1925/2012), toda experiência compreende dois componentes indissociáveis: um componente que ele chama de ativo, experimenting, ou seja, a ação do sujeito sobre o mundo; e outro que ele chama de passivo, experiencing, que seria a provação cognitiva, corporal e afetiva do sujeito da ação do mundo sobre ele.

Assim, somente há experiência se, de um lado, a ação do sujeito sobre o mundo é uma ação de transformação, seguida de mudanças concretas que ele comprova, e, de outro, se o sujeito estabelece, por meio da reflexão, uma relação entre sua ação e as mudanças comprovadas como tais. Ou seja, não se trata de apenas agir sobre o ambiente ou de comprovar a ação do mundo sobre si mesmo uma vez que, para 
que a experiência se estabeleça, é preciso uma conexão entre essas duas coisas.

Assim, para Dewey (1938/2011; 1925/2012), experiência e atividade são indissociáveis: "se o sujeito age, se ele prova as consequências de sua ação e, sobretudo se ele se engaja em um exercício reflexivo é unicamente no quadro de uma atividade finalizada e não pela "beleza do gesto"' (BOURGEOIS, 2013, p. 20).

De qualquer modo, cabe observar que apesar da importância da experiência para a educação, as problematizações postas por Dewey foram formuladas majoritariamente em termos de educação formal e no âmbito de um sistema de ensino institucionalizado.

De certa forma, essa discussão da experiência como fonte de aprendizagem, ainda que com significativas diferenças como se verá adiante, também está presente nos ciclos de aprendizagem propostos por Kolb (1984), na década de 70/80 por meio de sua teoria da aprendizagem experiencial elaborada na perspectiva da formação de adultos.

Essa teoria consiste, justamente, em uma abordagem sobre o desenvolvimento do adulto em que a profissionalidade é vista como um percurso permanente de aprendizagem desde que o indivíduo possa se apropriar de suas experiências de atuação profissional. De acordo com Kolb (1984):

Aprendizagem experiencial é o processo pelo qual o conhecimento é criado por meio da transformação da experiência. Esta definição enfatiza [...] que o conhecimento é um processo de transformação, sendo continuamente criado e recriado... A aprendizagem transforma a experiência tanto no seu caráter objetivo como no subjetivo [...]. Para a compreensão da aprendizagem, faz-se necessário compreender a natureza do desenvolvimento e vice-versa (p. 38, tradução nossa).

Aprender pela experiência não significa que qualquer vivência redunde em aprendizagem, haja vista que a apropriação dos saberes procedentes da experiência demanda processos contínuos de ação e reflexão diretamente vinculados às dimensões concreta/abstrata e ativa/reflexiva, base do ciclo de aprendizagem. Nas palavras de Pimentel (2007): 
A experimentação é vital para se estabelecer relações entre prática e teoria, visando promover o desenvolvimento profissional. Com a experiência concreta, ideias, valores, crenças e histórico pessoal de aprendizado são peças de um mesmo tabuleiro, em que apreender novos conceitos e maneiras de reorientá-los principia um processo ascendente e dialético de aprendizagem (p. 166).

Para Kolb (1984), o sujeito primeiro age, depois, reflete sobre sua ação, conceitualizando-a, teorizando-a para, aí sim, retornar à ação, à prática, entendida como experiência concreta e fruto desse vai e vem. Nesse sentido, a experiência para esse autor passa a ser vista tanto como objeto do pensamento e da aprendizagem (reflete-se sobre sua experiência, sobre sua prática) como fonte de aprendizagem ${ }^{4}$ (aprende-se a partir da experiência e da prática) (BOURGEOIS, 2013).

O ciclo de aprendizagem proposto por Kolb (1984) fundamenta-se, justamente, na articulação desses três elementos: a experiência tal como ela é vivida pelo sujeito em um dado contexto, a compreensão desse contexto e a construção de saberes a partir desse contexto. Nesse processo, ele distingue claramente pensamento e ação, ao contrário de Dewey (1938/2011) que refuta essa dicotomia, defendendo que pensamento e ação são funções coordenadas da atividade do sujeito em que a experiência não pode ser assimilada exclusivamente à ação, uma vez que ela não é nem objeto e nem fonte do pensamento e da aprendizagem, como considera Kolb (1984), mas sim, sua matriz (BOURGEOIS, 2013) ${ }^{5}$.

Outro autor, pioneiro no campo da formação de adultos e para o qual a experiência é um conceito fundamental, é Malcolm Knowles que sistematiza uma teoria, a andragogia, voltada, justamente, para a aprendizagem dos adultos, desvinculando-a da já conhecida pedagogia que,

4 Kolb (1984) define a aprendizagem como "o processo pelo qual o saber é criado por meio da transformação da experiência" (p. 155 - tradução nossa).

5 Incorpora-se aqui, ainda que muito rapidamente, parte das críticas sobre o ciclo de aprendizagem elaboradas por Bourgeois (2013) e Finger (1989) que inclui, por exemplo, a ideia, no caso das elaborações de Kolb e Knowles, de que a experiência é apresentada como algo vivido de modo individual, sem considerar o contexto do sujeito. 
segundo ele, não contemplaria as especificidades da natureza da aprendizagem dos adultos (1973/1990).

De acordo com Balleux (2000), no contexto do debate que opõe pedagogia e andragogia, Knowles define o adulto em função de sua capacidade de usar seu repertório de experiências, elemento determinante da identidade do adulto. Grosso modo, o modelo andragógico fundamenta-se em cinco proposições centradas sobre a aprendizagem do adulto e sobre os meios para seu favorecimento: 1) o adulto precisa saber o porquê de uma demanda de aprendizado; 2) o adulto se autodirige; 3) ele possui um repertório de experiências que acabam por ser sua fonte de aprendizagem; 4) a aprendizagem é reforçada quando orientada para as necessidades do desenvolvimento e para os papéis sociais; e 5) as necessidades educativas dos adultos são centradas sobre seus interesses (KNOWLES, 1973/1990).

E no que consistiria, segundo Knowles (1973/1990), a especificidade da educação de adultos em relação à educação da criança ou do jovem em fase escolar? Justamente a experiência, considerada fundamental tanto na motivação para aprender como na aprendizagem propriamente dita. Encontram-se, atualmente, ideias amplamente concebidas em múltiplos campos da formação que partem das premissas da andragogia e da importância da experiência para todo tipo de aprendizagem: "é preciso partir da experiência das pessoas, considerar sua experiência, mobilizar a experiência, os saberes devem fazer sentido em relação à experiência... etc.”.

Essas diferentes perspectivas teóricas, elaboradas em épocas e contextos distintos e muito brevemente expostas aqui, elegeram a experiência como algo fundamental para a compreensão da aprendizagem dos adultos sendo, implícita ou explicitamente, ainda dominantes nas atuais discussões sobre essa temática ${ }^{6}$.

6 Cabe destacar aqui que o avanço das discussões no campo da formação de adultos levou, inclusive, à junção, de ambas as noções, aprendizagem e experiência em uma única fórmula, algo ainda não elaborado nos estudos de Dewey (1938/2011), Kolb (1984) e Knowels (1973/1990). Para uma discussão sobre diferentes definições de aprendizagem e o modo como a experiência está mais ou menos integrada em suas formulações, ver Balleux (2000). 
Se se pensar o campo atual sobre a formação e a profissionalização de professores, muitos também têm sido os estudos que colocam em evidência o conceito de experiência para a compreensão da ação docente, como é o caso, por exemplo, dos trabalhos desenvolvidos por Tardif, Lessard e Lahaye (1991), Josso (1991), Tardif, (1993), Schön (1994), Therrien (1998) e Perrenoud (2000) e que tiveram impacto direto na produção acadêmica brasileira.

Tais estudos, ao focalizarem a análise do trabalho docente nessa perspectiva, têm mostrado a importância da experiência, incluindo suas expressões e comunicação, na constituição dos saberes docentes articulados ao contexto social mais amplo, muito embora poucas são as análises que se dedicam à compreensão da vivência, da elaboração e da comunicação dessa experiência de acordo com a organização conceitual proposta por Barbier (2013b).

Feitas essas considerações e para fornecer subsídios empíricos para a discussão que vem sendo realizada, apresenta-se, a seguir, o recorte sintético de uma pesquisa realizada com 46 docentes de diferentes disciplinas ${ }^{7}$ de escolas públicas de $5^{\circ}$ a $9^{\circ}$ ano de duas cidades do interior de São Paulo (pequeno e médio porte).

A grande maioria dos respondentes é do sexo feminino (77\%), atribui-se a cor branca (84\%) e tem filhos (66\%). Quanto à faixa etária: $44,4 \%$ dos entrevistados pertencem à faixa de 41 a 50 anos e $44,2 \%$ estão divididos igualmente entre professores nas faixas de 31 a 40 anos e de 51 a 60 anos.

A maioria dos professores possui mais de 15 anos de magistério (55\%), sendo 46,7\% professores com mais de 20 anos de profissão, 24,4\% com até 10 anos de profissão e 28,9\% de professores com 11 a 20 anos de profissão.

Outra característica que vale menção refere-se à formação complementar dos participantes da pesquisa: 49\% dos professores

7 São elas: Artes, Ciências físicas e biológicas, Filosofia, Geografia, História, Língua Portuguesa, Matemática e Química. 
entrevistados já fizeram algum curso de curta duração, 44\% fizeram curso de especialização e $7 \%$ têm mestrado.

Após autorização da escola, foi feito um convite aos professores que quisessem participar da pesquisa. Em dia e horário previamente agendados, foi realizada uma entrevista semiestruturada em torno da problemática da experiência e que se iniciava com um questionário contendo informações sobre o perfil.

Em decorrência do objetivo deste texto, elencou-se, como objeto de recorte, a diversidade de entendimento da noção de experiência do ponto de vista dos professores participantes da pesquisa. Assim, serão apresentados a seguir alguns dos dados obtidos por meio das respostas às seguintes questões norteadoras do roteiro de entrevista: a) O que é experiência na profissão docente? e b) Em relação à sua profissão, como você definiria um professor experiente? Esses dados foram submetidos a um tratamento de análise de estatística textual por meio do programa Alceste $^{\odot}$ (REINERT, 1990).

De modo geral, ao se referirem à experiência, independentemente das características de perfil, do tempo de serviço e da disciplina ministrada, os participantes da pesquisa ressaltam aspectos de natureza bem distintas e que fazem referência, sobretudo, à três zonas semânticas que se entrelaçam e se incorporam mutuamente, estando em constante interação em sua produção discursiva: a) experiência como processo e produto da ação e reflexão; b) experiência como continuum; c) experiência como (não) temporalidade ${ }^{8}$.

\section{a) Experiência como processo e produto da ação/reflexão}

Essa zona semântica apresenta excertos da produção discursiva dos participantes da pesquisa, que faz referência à experiência como

( Todos os direitos reservados à Société IMAGE (1986-2000). Autor: Max Reinert (Licença CNRS/ UTM).

8 De modo geral, essas zonas semânticas aparecem entrelaçadas na produção discursiva dos participantes da pesquisa, motivo pelo qual não se usou aqui o conceito de categoria. 
capacidade de elaboração de soluções frente aos problemas ou dificuldades do cotidiano e como estratégia formativa, como pode ser observado a seguir:

Ser experiente hoje não significa dar mais aulas em termos de tempo do que outros colegas. Ser experiente hoje significa compreender as transformações que estão ocorrendo no mundo e procurar adaptar-se à estas transformações. [...] Significa reflexão. Buscar uma melhor maneira de agir para aquele momento que você está vivendo. Isso para mim seria ter experiência (Professor, Formação em Matemática, entre 16 e 20 anos de carreira).

Experiência é eu adquirir cada vez mais uma habilidade para lidar com os que estão vindo aí pela frente. Isso depende da variável tempo, das experiências que você troca com colegas, com o projeto que é desenvolvido, com a clientela que você convive, com tudo, com os alunos que você tem [...] (Professora, Formação em Pedagogia, entre 16 e 20 anos de carreira).

Eu acho que a experiência é muito importante, acho que tem a ver com tempo [...] um tempo em que você pensa, não em um tempo automático [...] Acho que a experiência é a prática repensada cotidianamente (Professora, Formação em História, com mais de 20 anos de carreira).

Realça-se aqui não apenas a capacidade de refletir sobre o que acontece com o sujeito no próprio fazer profissional, na e pela atividade, mas o fato mesmo de que essa experiência deva ter um impacto na melhoria de competências e habilidades desse mesmo fazer. Ou seja, a experiência é identificada como algo que se vive e que é acessível à própria pessoa que a vive, como uma espécie de saber acumulado que pode ser aberto a novas possibilidades de ação.

Embora acessível, foram poucos os docentes que indicaram que essa experiência pode ser comunicada e transmitida ${ }^{9}$, como mostra o

9 Muito embora não tenha existido, em nenhuma das produções discursivas uma reflexão sobre esse processo complexo de elaboração e comunicação e da transmissão da experiência. A respeito ver, sobretudo, Barbier (2013b). 
excerto a seguir que faz referência ao reconhecimento e valorização da experiência como estratégia formativa:

[...] a gente vai passando por tantas dificuldades, você vai se deparando na vida com tantas dificuldades, situações diferentes que quando a gente tem um certo tempo, a gente já adquiriu uma experiência, a gente já está calejada naquilo [...]. Os professores novos que chegam para você e pedem uma opinião, ou que pedem como se ensina determinado conteúdo, isso é muito bom. Isso é uma experiência, porque eles estão te chamando de experiente, eles querem, eles acham que aquilo que você trabalhou deu certo e eles querem aprender também. Então você está passando a sua experiência para outra pessoa (Professora, Formação em Pedagogia, entre 16 e 20 anos de carreira).

O que chama a atenção neste último excerto é justamente a ideia de que a experiência, apesar de pressupor uma apropriação pessoal, pode ser transmitida. Não tal e qual, pois afinal, o sujeito sempre é o autor de sua própria aprendizagem. Mas, como lembra Bourgeois (2013), "[...] nesse trabalho intervêm, necessariamente, fontes externas ao sujeito, trazidas por um outro, em um processo relativamente intencional de transmissão" (p. 34, tradução nossa).

\section{b) Experiência como continuum:}

Nos trechos abaixo, a experiência não surge como um processo ou como um produto: ela é imanente à atividade humana. Nesse sentido, que se pensou nessa zona semântica como um continuum da experiência.

Mesmo agora que eu estou para me aposentar, toda classe que eu entro, eu entro tremendo, eu entro desassossegado, eu entro inseguro... E eu adoro isso, adoro entrar na sala, mesmo tendo certo domínio e me sentir inseguro, isso é maravilhoso, isso é experiência pois não tem como chegar assim, pronto, acabado. Experiência é o fazer fazendo. É a vida mesmo (Professor, Formação em Geografia, mais de 20 anos de carreira). 
Experiência é tudo o que fazemos.... basta estar vivo para termos experiência (Professor, Formação em Filosofia, entre 2 e 5 anos de carreira).

Por outro lado, esse continuum traz algumas dificuldades para a compreensão dos usos da experiência. Nesse ponto, remete-se a um trecho de Zeitler (2013) particularmente esclarecedor acerca desse aspecto: "A experiência aparece como um deus ex machina do desenvolvimento humano: ao explicar tudo, ela não explica nada" (p. 136, tradução nossa, grifos do autor).

\section{c) A experiência e a temporalidade:}

O que chama a atenção nessa zona semântica, ao contrário das demais, é o posicionamento contrário existente acerca da relação entre experiência e temporalidade. Assim, enquanto para alguns a experiência remete à história de vida do docente e ao tempo de carreira, para outros, ela se associa muito mais ao sentido dado à atividade docente, como é o caso dos excertos a seguir:

Eu tenho colegas aqui já aposentados, estão no segundo cargo com problemas terriveis com os alunos. E que experiência este professor tem em vinte e cinco anos de profissão? A experiência serviu para quê, ele continua brigando com aluno do mesmo jeito. Então não é experiência profissional, é seu interior, a gente tem que evoluir, acompanhar. A experiência advinda do tempo não é o que faz diferença na sala de aula. O que faz a diferença na sala de aula é o que você sente quando está lá dentro (Professora, Formação em Ciências Físicas e Biológicas, entre 16 e 20 anos de carreira).

Ser experiente hoje não significa dar mais aulas em termos de tempo do que outros colegas. Ser experiente hoje significa compreender as transformações que estão ocorrendo no mundo e procurar se adaptar a estas transformações... (Professor, Formação em Matemática, entre 11 e 15 anos de carreira). 
São os anos de sala de aula mesmo, que a gente vai convivendo com os alunos... é o dia a dia. A experiência está relacionada com o tempo de magistério e a formação. O tempo é importante para gente... (Professor, Formação em Letras, entre 16 e 20 anos de carreira).

Experiência são estes anos todos que eu já trabalhei que são vinte e três anos de estado com mais sete anos que eu estive dentro de uma escola infantil [...]. É o tempo, é o que vai acontecendo, é o dia a dia mesmo, afinal o que faz a experiência a não ser a prática, você está ali fazendo a experiência (Professora, Formação em Pedagogia, mais de 20 anos de carreira).

Observa-se na produção discursiva dos participantes da pesquisa certa ideia de linearidade: aquilo que se adquire com a experiência usase (ou deveria ser usado) para enfrentar situações novas. Contudo, não transparece a ideia da experiência enquanto movimento de reelaboração e de ressignificação.

Evidentemente que há um grande número de outros exemplos que não cabe aqui recuperar. Contudo, nesse rápido recorte e para além da diversidade de usos do termo experiência, gostaria de se pontuar três aspectos importantes da produção discursiva analisada. O primeiro, é que, de modo geral, experiência aparece intimamente associada ao trabalho docente reforçando a ideia de que o professor se forma na e pela atividade. Segundo, mesmo a experiência sendo considerada ora como produto, ora como processo, ora como continuum, ela surge quase sempre como um qualificativo de um bom profissional, o que mostra que, para os participantes da pesquisa, experiência e reconhecimento caminham juntos. E, por fim, a experiência permite um retorno ao sujeito na medida em que “o sujeito que faz uma experiência não é um sujeito 'epistêmico', mas um sujeito concreto, dotado de valores e de intenções, engajado no aqui e agora em uma dada atividade inserida em uma dada situação" (BOURGEOIS, 2013, p. 19, tradução nossa). 


\section{Considerações finais}

Usos tão diversos, em tão diferentes épocas e esferas do saber científico fazem com que esse conceito continue ainda como uma das noções menos elucidadas das ciências sociais, o que indica a atualização da observação feita por Gadamer (1976) em meados da década de 1970 a esse respeito e que a fala dessa professora sintetiza tão bem: "O que que é experiência? Eu não sei definir isso! Acho que experiência são todos os 'pepinos' que já tive na vida...." (Professora, Formação em Pedagogia, mais de 20 anos de carreira).

Esse panorama complexo indica a necessidade de uma desnaturalização da noção de experiência e de suas expressões, de modo a discutir a diversidade de seus usos, sobretudo no campo da formação e da profissionalização docentes. Usos esses atrelados também a certas concepções de formação e de profissionalização muitas vezes, elas próprias, naturalizadas na medida em que escondem posicionamentos epistêmicos bastante diversos.

Sem desconsiderar essa complexidade, a questão que fica aqui é o fato de que os usos da experiência, no âmbito da formação de adultos, podem levar a um esvaziamento desse conceito por três razões principais: primeira, porque a experiência só pode ser considerada educativa quando amplia a qualidade das interações (DEWEY, 1938/2011) de modo a desenvolver formas de se situar, de pensar e de ação próprias à realização de um trabalho de qualidade (MAYEN, 2014, p. 122).

Como consequência disso, tem-se a segunda razão de um possível esvaziamento, na medida em que, ao reduzi-la a "[...] um caráter situado, não sistemático, e não passível de transferência e generalização" (CRUZ JUNIOR, DELLA FONTE, LOUREIRO, 2014, p. 211, grifos dos autores) incorre-se no risco de remetê-la a uma esfera de imediaticidade muito comum nas oficinas chamadas de troca de experiências, por exemplo (idem, p. 213).

Por fim, há que se fazer referência às próprias dificuldades de se trabalhar com o conceito de experiência, cuja particularidade nos escapa seja em uma perspectiva epistemológica, seja em uma perspectiva 
do senso comum, na medida em que, pela plasticidade própria à sua natureza, ele só pode ser definido a partir do uso que se faz dele, o que não anula sua reivindicação de validade universal para além de suas condições de validade histórica ${ }^{10}$.

\section{Referências}

AMATUZZI, M. Experiência: um termo chave para a Psicologia. Memorandum, 13, p. 0815. Disponível em: <http://www.fafich.ufmg.br/ memorandum/ a13/01Amatuzzi.pdf>. Acesso em: 09 ago. 2016.

BALLEUX, A. Évolution de la notion d'apprentissage expérientiel en éducation des adultes: vingt-cinq ans de recherche. Revue des sciences de l'éducation, v. 26, n. 2, p. 263-286, 2000.

BARBIER J.-M. Expérience, apprentissage, éducation. In: ALBARELLO, L.;et al. (Dir.). Expérience, activité, apprentissagei. Paris: PUF, 2013a.

BARBIER J.-M. Vécu, élaboration et communication de l'expérience. In: BARBIER J.-M. ; THIEVENAZ, J. (Dir.) Le travail de l'expérience. Paris: L’Harmattan, 2013b. p. 13-37.

BOURGEOIS, E. Expérience et apprentissage. La contribution de John Dewey. In : ALBARELLO, L. ; BARBIER, J-M ; BOURGEOIS, E. ; DURAND, M. (Eds.), Expérience, activité, apprentissage. Paris: PUF, 2013. p. 13-38.

BRASIL. Sistema Nacional de Certificação Profissional: proposta governamental. Brasília, DF: MTE, set. 2005, 12 p. Disponível em: <http://acesso.mte.gov.br/ data/files/FF8080812BE4CA7C012BE50810512259/proposta_governamental. pdf>. Acesso em: 02 ago. 2016.

COMETTI, J-P. Présentation. L'expérience dans la philosophie de John Dewey. In : DEWEY, J. Expérience et nature. Paris: Gallimard, 2012. [1925]. p.7-18.

10 Pensa-se aqui, especificamente, nas discussões de Koselleck (2006) acerca do conceito de espaço de experiência. A respeito, ver também Villas Bôas (2009). 
CRUZ JUNIOR, A. F.; DELLA FONTE, S. S.; LOUREIRO, R. Formação continuada de professores: quando a experiência e os saberes docentes se limitam a vivência. Pro-posições, v. 25, n. 2 (74), p. 197-215. maio/ago. 2014.

DEWEY, J. Experiência e educação. 2a ed. Petrópolis : Vozes, 2011. [1938].

DEWEY, J. Expérience et nature. Paris: Gallimard, 2012. [1925].

DOMINICÉ, P. La formation expérientielle: un concept importé pour penser la formation. In: COURTOIS, B.; PINEAU, G. (Orgs.). La formation expérientielle des adultes. Paris: La Documentation Française, 1991. p. 53-58.

FINGER, M. Apprentissage expérientiel ou formation par les expériences de la vie? Éducation permanente, n. 100/101, p. 39-45, 1989.

GADAMER, H.-G. Vérité et Méthode. Les grandes lignes d'une herméneutique philosophique, trad. partielle E. Sacre et P. Ricoeur. Paris: Seuil, 1976.

JOSSO, M-C. L'expérience formatrice: un concept en construction. La formation expérientielle des adultes. Paris: La documentation française, 1991. p. 191-199.

KNOWLES, M. S. The adult learner: A neglected species. Houston: Gulf Publishing Company. Revised Edition, 1973/1990.

KOLB, D. A. Experiential learning. Englewood Cliffs, New Jersey: Prentice Hall, 1984. Disponível em: 〈http://www.scielo.br/pdf/epsic/v12n2/a08v12n2.pdf〉. Acesso em: 15 maio 2016.

KOSELLECK, R. Futuro passado: contribuição à semântica dos tempos históricos. Rio de Janeiro: Contraponto/PUC-Rio, 2006.

LANDRY, F. La formation expérientielle: origines, définitions et tendances. Education Permanente, v. 100/101, p. 13-22, 1989.

LARROSA, J. Notas sobre a experiência e o saber de experiência. Rev. Bras. Educ. n. 19 p. 20-28, 2002. Disponível em: <http://www.scielo.br/scielo. php? script=sci_arttext $\&$ pid $=$ S1413-24782002000100003\&lng=en\&nrm =i so>. Acesso em: 15 maio 2016. ISSN 1413-2478. http://dx.doi.org/10.1590/ S1413-24782002000100003. 
MAYEN, P. Expérience professionnelle. In: JORRO, A. (Dir.). Dictionnaire des concepts de la professionnalisation. Louvain-la-Neuve: De Boeck, 2014. p. 121-125.

MAYEN, P. Expérience et formation des adultes. In: BARBIER, J-M.; BOURGEOIS, É.; CHAPELLE, G.; RUANO-BORBALAN, J-C. (Eds.). Encyclopédie de la formation. Paris: Presses Universitaires de France, 2009. p. 765-780.

PERRENOUD, P. Dez novas competências para ensinar. Porto Alegre: Artes Médicas, 2000.

PIMENTEL, A. A teoria da aprendizagem experiencial como alicerce de estudos sobre desenvolvimento profissional. Estudos de Psicologia, v. 12, n. 2, p. 159-168, 2007.

REINERT, M. Alceste, une methodologie d'analyse des donnees textuelles et une application: Aurelia de Gerard de Nerval. Bulletin de Methodologie Sociologique, $\mathrm{n}$. 26, p. 24-54, mar. 1990.

ROBIN, J-Y. La carrière : adieu la formation, vive l'accompagnement. In: BOUGÈRE, G. ; ULMANN, A-E. (Dir.). Apprendre de la vie quotidienne. Paris: PUF, 2009. p. 183-194.

SCHÖN, D. A. Le praticien réflexif. Montréal: Les Éditions Logiques, 1994.

TARDIF, M.; LESSARD, C.; LAHAYE, L. Os professores face ao saber. Esboço de uma problemática do saber docente. Porto Alegre: Pannônica, 1991.

TARDIF, M. Savoirs et expérience chez les enseignants de métier: Quelques pistes et jalons concernant la nature des savoirs d'expérience. In: HENSLER, H. (Dir.). La recherche en formation des maîtres. Québec: Université de Sherbrooke: Éditions du CRP, 1993.

THERRIEN, J. Expérience professionnelle et savoir enseignant: La formation des maîtres mise en question. In: TARDIF. M. ; LESSARD, C.; GAUTHIER, C. (Dir.). Formation des maîtres et contextes sociaux - Perspectives internationnales. Paris: Presses Universitaires de France, 1998, p. 231-260. 
VILLAS BÔAS, L. Brasil: ideia de diversidade e representações sociais. São Paulo: Annablume, 2010.

ZEITLER, A.; BARBIER, J-M. La notion d'expérience, ente langage savant et langage ordinaire. Recherche et formation. n. 70, p. 107-118, 2012.

ZEITLER, A. Construction de l'expérience, habitudes d'interprétation et signification du vécu. In: ALBARELLO, L. ; BARBIER, J-M ; BOURGEOIS, E. ; DURAND, M. (Eds.), Expérience, activité, apprentissage. Paris: PUF, 2013. p. 135-160.

Recebido: 22/08/2016

Received: 08/22/2016

Aprovado: 10/09/2016 Approved: 09/10/2016 
